\title{
REAÇÃO DE RESISTÊNCIA DE GENÓTIPOS DE TOMATEIRO (Lycopersicum spp.) A INFECÇÃO POR Rhizoctonia solani KUHN
}

\author{
A.M. RODRIGUES CASSIOLATO \\ Departamento de Genettca, ESALO/USP, C.P., 83, CEP: 13418-900, Plracicaba,SP \\ I.S. de MELO \\ CNPMA/EMBRAPA, C.P. 69, CEP: 13820-000, Jaguariana, SP
}

\begin{abstract}
RRSUMO: Dada a importancia da tomaticultura no Brasil e das enfermidades que atacam esta cultura, da mesma forma que visando futuros estudos em programas de melhoramento vegetal para resistencia a patógenos, este trabalho teve por objetivos: avaliar o grau de patogenicidade de quatro isolados de Rhizoctonia solant obtidos de plantas doentes de tomateiro (RT), berinjeles $\left(R_{1}\right.$ e $\left.\mathbf{R B}_{2}\right)$ e pimentho (RP), em viveiros, frente a 9 genotipos de tomateiros e avaliar a reaç̄o de resisttencia de 73 genctipos de tomateiros ao $\boldsymbol{R}$. solani. Nos experimentos utilizou-se solo esterilizado, em condiçies de casa de vegetacão. Para o experimento I, os isolados de $\boldsymbol{R}$. solant, oriundos das plantas de tomateiro (RT) e berinjela (RB) foram igualmente mais patogenicos que os isolados de berinjela $\left(\mathbf{R B}_{1}\right)$ e pimentio (RP), com relactio aos 9 genctipos de tomateiro testados. Pode-se diser que os isolados variaram em graus de agressividade. Quanto ds reaçes de resistencia a $\boldsymbol{R}$. solani, observon-se que os diferentes genotipos nio diferiram estatisticamente entre si. Com releção ao experimento II, entre os 73 genotipos de tomateiro (inchuindo espécies selvagens, variedades macionais e introduç̄̄es), pode-se observar que houve grande variabilidade quanto a reação de resistencia a $\boldsymbol{R}$. solant (isolado do tomateiro - RT), com percentusis de sobrevivencia de plantas variando de $91 \%$, para a cultivar Quinck Pick, ate 0\% de sobrevivencia para o genotipo LA-462. Näo foi verificada imunidade em nenhum material avalindo e sim nfreis de resistencia, onde esta, expressa em percentagem de sobrevivtocia, ccorrea de uma mancira continua, desde uma rescho de suscetibilidade ate altos niveis de reaistlncia.

Deceribares: reaçio de resistencia, genotipos de tomateiros, patogenicidade, Rhzoctonla solanl
\end{abstract}

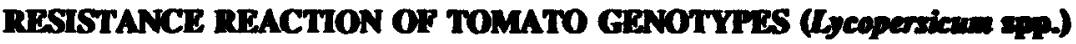 TO Bhizoctomin solmai KUIN}

SUMMARY: The present study was undertaken with the following objectives: 1) to evaluate the level of pathogenicity of four Rhizoctonia solani isolates obtained from diseased tomnto plants $(\mathbf{R T})$, from ezelant $\left(\mathbf{R B}_{1}\right.$ and $\left.\mathbf{R B}_{2}\right)$, and pepper (RP) and tested on 9 tomato genotypes growa in experimentol plots; and 2) evoluate the resistance reaction of 73 tomato genotypes to the pathogen. Experiments were performed in greenluouse wsing sterilized soil. In experiment $I, R$. solanl isolates from $R T$ and $R_{2}$ plonts were identically more pathogenic $\mathbf{R B}_{1}$ and $\mathbf{R P}$. In experiment $\mathrm{I}$, wide variability in the resistance reaction to $R$. solant (isolated from a tomato plant - RT) was observed among the 73 tomato genotypes (which included wil species, Bravilian varieties and introduced material), with percentage of plant survival ranging from 91\% for the cultivar Quick Pick to 0\% for the genotype LA-462. None of the materials tested showed immunity, but different levels of resistance were observed, ranging from susceptibility to high resistance, as expressed by the survival percentages.

Kog Worls: resistance reaction, tomato genotypes, pathogenicity, Rhizoctonia salant

\section{INTRODUÇÃo}

O tombamento ou "damping-off" considerado um dos maiores problemas das doenças de plantas, porem, o seu controle ou prevenção é dificultado pelo envolvimento de muitos patogenos que atuam isoladamente ou combinados nos mais de 80 tipos de plantas de viveiros (STEPHENS et al., 1981). Ele caracteriza-se por ser uma doença que ataca a cultura na fase de plantulas, podendo ocorrer na pré e pós-emergência. No primeiro caso, os cotilédones são atacados antes de emergirem e, no segundo, os patógenos atingem a plântula já emergida, sendo uma ação fulminante e rápida. 0 ataque ocorre na região do colo provocando um anelamento e levando a uma coloração marrom. 
Os fungos causadores do tombamento são naturais do solo, onde sobrevivem saprofiticamente ou através de estruturas de repouso. Seus propágulos são disseminados através da água de irrigação, ventos ou partículas de terra aderidas a implementos agrícolas. A penetração desses fungos se dá diretamente através das paredes celulares da epiderme da raiz ou hipocótilo com a subsequente invasão, pelo micélio dos tecidos da planta, que acabam por serem degradados pela ação de enzimas ou toxinas (KRUGNER, 1980).

Os fungos causadores de tombamento pertencem a diferentes classes taxonômicas, são todos saprofíticos e polífagos, o que torna difícil a determinação das plantas que podem hospedá-los. Dentre os mais comuns encontra-se a Rhizoctonia solani (MINAMI \& HAAG, 1979; TOKESHI \& CARVALHO, 1980).

$R$. solani sobrevive como escleródios ou hifas espessadas associadas a estas plantas. Apresentam grande variabilidade quanto a gama de hospedeiros, produção de escleródios e patogenicidade. A tendência atual para classificação dos diversos isolados do $R$. solani é através da reação de anastomose de hifas. Essa reação tem explica-ções na taxonomia em virtude da possibilidade de divisões sub-específicas (PARMETER JUNIOR \& WHITNEY, 1970; PARMETER JUNIOR et al., 1969; SHERWOOD, 1969).

O controle químico efetivo desta doença tem sido inconsistente. As medidas preventivas recomendadas, como a rotação de cultura, têm se mostrado pouco eficientes devido a grande longevidade dos escleródios e da grande diversidade de hospedeiros suscetíveis ao patógeno (BAKER, 1970). A ausência de rotação de culturas pode favorecer o acúmulo de escleródios no solo, aumentando o nível de inóculo e diminuindo a eficiência dos fungicidas. Um importante passo que poderia fornecer medidas mais eficientes para o controle da doença, seria a seleção de novos cultivares ou clones com diferentes níveis de resistência ao patógeno (BOOSALIS \& SCHAREN, 1959, citados por BENSON \& BAKER, 1974). Por outro lado, o conhecimento de diferentes graus de patogenicidade do fitopatógeno $e$ de grande interesse, pois variedades de plantas suscetíveis inoculadas com um fungo fracamente patogênico poderão mostrar-se altamente resistentes ao patógeno. Entretanto, se estas mesmas forem inoculadas com linhagens de alta patogenicidade poderão ser completamente destruídas.
$\mathrm{Na}$ oportunidade vale salientar que são poucos os dados sobre plantas de tomateiro quanto a reações a $R$. solani. Nesse sentido o uso de variedades geneticamente resistentes, adaptadas às nossas condiçôes, figuram como um importante método de controle da doença. As variedades de tomateiro ora plantadas em nosso meio carecem de resistência a este fitopatógeno.

Este trabalho teve por objetivos avaliar o grau de patogenicidade de quatro isolados de $R$. solani obtidos de plantas doentes de tomateiro (RT), berinjelas $\left(\mathrm{RB}_{1}\right.$ e $\left.\mathrm{RB}_{2}\right)$ e pimentão (RP), em viveiros da ESALQ/USP; e a reação de resitência de setenta e três genótipos de tomateiro ao patógeno $R$. solani.

\section{MATERIAL E MEtTOdos}

$O$ experimento foi conduzido em 1986/87, em casas de vegetação e laboratórios dos Departamentos de Fitopatologia Genética da Escola Superior de Agricultura "Luiz de Queiroz"/USP, Piracicaba, SP, Brasil, latitude de $22^{\circ} 42^{\prime} 30^{\prime \prime}$ 'S. O substrato constituiu-se de uma mistura de três quartos de solo terra roxa estruturada - série Luiz de Queiroz com um quarto de esterco animal, ao qual foi adicionado adubo químico, bagacilho de cana-de-açucar e areia lavada de rio, autoclavado por duas horas a 1 atmosfera de pressão. A amostra indicou o $\mathrm{pH}=6,0$.

Os 73 genótipos de tomateiro em questão receberam números através dos quais serão citados. As sementes listadas até o número 55 foram cedidas pela Sementes Agroceres S.A., Igarape, MG, e as demais, pela Northrup King Co., Gilroy, Califórnia - USA.

Os quatro isolados de $R$. solani foram obtidos a partir de isolamentos feitos do colo de plântulas apresentando os sintomas de tombamento. As coletas foram realizadas em diferentes plantas de tomateiro (RT), berinjela $\left(R_{1}\right.$ e $\left.R B_{2}\right)$ e pimentão (RP) oriundas de viveiros da ESALQ/ USP.

Os pedaços de colo das plântulas foram lavados em água corrente, água destilada e transferidos para placas de Petri contendo meio BDA (extrato de batatas, $200 \mathrm{ml}$; glucose, $18 \mathrm{~g}$; ágar, $16 \mathrm{~g}$; Ǵgua destilada $760 \mathrm{ml}$ ) mais $200 \mathrm{ppm}$ de sulfato de estreptomicina. As placas foram mantidas à temperatura ambiente $\left(25^{\circ}-30^{\circ}\right)$. O inóculo constou de discos contendo crescimento micelial (10 mm de diâmetro) tomados das margens das colônias e transferidos para pontos equidistan- 
tes do vaso $(1 \mathrm{Kg})$, sendo colocados a $2 \mathrm{~cm}$ de profundidade (STEPHENS et al., 1981). Em vasos de polietileno de $1 \mathrm{Kg}$ utilizou-se dois discos enquanto que para os de $2 \mathrm{Kg}$ foram utilizados tres discos.

Os experimentos foram realizados utilizando-se delineamento experimental inteiramente casualizado. Para os casos dos dados expressos em percentagem foram feitas transformações para arc sen $\sqrt{ } \%$. No tocante ao teste de médias foi aplicado o teste de Tukey em nível de $5 \%$ de probabilidade (STEEL \& TORRIE, 1980).

Experimento I - Avaliação do Grau de Patogenicidade de Isolados de $R$. solani: $O$ primeiro experimento teve por objetivo avaliar, quanto ao grau de patogenicidade quatro isolados de $R$. solani $\mathrm{em}$ nove genótipos de tomate, assim como observar o grau de resistência destes genótipos frente aos isolados de $R$. solani.

Foi conduzido em vasos de polietileno com capacidade de $1 \mathrm{Kg}$ de solo, por um periodo de 35 dias. A inoculação foi efetuada no décimo dia ap6s o plantio. A colheita do experimento realizou-se em intervalos de $3 \mathrm{em} 3$ dias a partir do décimo terceiro dia de semeadura.

O delineamento experimental foi inteiramente casualizado, com parcelas subdivididas, com três repetiçóes e doze plantas por vaso, além de testemunhas não inoculadas. As parcelas constaram de genótipos de tomateiros e as subparcelas dos isolados de $R$. solani.

Experimento II - Reação de genótipos de tomateiros a $R$. solani: $O$ experimento teve como objetivo avaliar 73 genótipos de tomateiro (TABELA 1) quanto ao grau de resistência, frente ao isolado de $R$. solani selecionado no experimento anterior com alto grau de patogenicidade - isolado de tomateiro - RT. Foi conduzido em sacos de polietileno, com capacidade de $2 \mathrm{Kg}$. A inoculação foi efetuada no décimo dia após o plantio. A colheita do experimento foi realizado de $3 \mathrm{em} 3$ dias, a partir do décimo terceiro dia de semeadura.

o delineamento experimental adotado foi inteiramente casualizado com cinco repetições e dez plantas por vaso.

\section{RESULTADOS}

- experimento I mostra que os isolados de $R$. solani diferiram estatisticamente entre si em nível de $1 \%$ de probabilidade pelo teste F (TABELA 1). Pelo teste de Tukey, em nível de
5\% de probabilidade (TABELA 2), os isolados puderam ser agrupados quanto a agressividade, ou seja, os isolados de tomateiro (RT) e de berinjela $\left(R B_{2}\right)$ foram igualmente mais agressivos $e$, os isolados de berinjela $\left(R_{1}\right)$ e de pimentão (RP), foram igualmente menos agressivos.

TABELA 1. Valores e significâncias dos quadrados médios e coeficientes de variação da análise de variância do Experimento I - Avaliação do Grau de Patogenicidade de Isolados de $R$. solani em tomateiro.

\begin{tabular}{lccc}
\hline Fontes de Variação & GL & QM & F \\
\hline Tratamento (T) & 8 & 471,2231 & 1,62 \\
Resíduo (a) & 18 & 290,4324 & \\
\hline Parcela & 26 & & \\
\hline Isolados (I) & 3 & 22584,0077 & 81,74 \\
Interação & 24 & 420,8888 & 1,52 \\
Resíduo (b) & 54 & 276,2746 & \\
\hline
\end{tabular}

\begin{tabular}{lll}
\hline CV (\%) & (a) $47,39 \%$ & (b) 46,21
\end{tabular}

- Significativo em nível de $1 \%$ de probabilidade pelo teste $F$

OBS: Análise feita com dados transformados em $\operatorname{arc} \operatorname{sen} \sqrt{ } \%$.

Quanto às reações de resistência dos genótipos de tomateiro a $R$. solani, observou-se que os diferentes genótipos não diferiram estatisticamente entre si. A interação entre isolados do patógeno $x$ genótipos de tomateiro não diferiram estatisticamente entre si, sugerindo que não existe dependéncia entre os isolados e os genótipos testados.

Apesar dos fenótipos de tomateiro não terem diferido estatisticamente entre si, toma-se de interesse comentar que o tomate Santo Antonio foi - que apresentou as menores taxas de sobrevivência, frente aos quatro isolados de $\boldsymbol{R}$. solani.

Como pode ser observadona TABELA 2, para qualquer que seja o genotipo escolhido, tem-se sempre a ordem de isolados de tomateiro (RT) e berinjela $\left(R B_{2}\right)$, e berinjela $\left(R_{1}\right)$ e pimentão (RP) no sentido de maior para menor capacidade de causar doença.

Da mesma maneira, para qualquer isolado escolhido, não existe uma ordem diferencial para o nível de resistência. 
TABELA 2 - Médias da porcentagem de sobrevivência de plantas de tomate no teste de seleção para o nível de patogenicidade à isolados de Rhizoctonia solani, em casa de vegetação. Piracicaba, SP., 1986.

Isolados de $R$. solani

\begin{tabular}{lcccr} 
Cultivares & $\mathbf{R T}$ & $\mathbf{R B}_{2}$ & $\mathbf{R B}_{\mathbf{1}}$ & $\mathbf{R P}_{2}$ \\
\hline 1. Heline & $30,56 \mathrm{a}$ & $27,78 \mathrm{a}$ & $100,00 \mathrm{~b}$ & $93,27 \mathrm{~b}$ \\
2. Alcobaça & $47,22 \mathrm{a}$ & $33,34 \mathrm{a}$ & $100,00 \mathrm{~b}$ & $97,22 \mathrm{~b}$ \\
3. Jubileu & $25,00 \mathrm{a}$ & $22,23 \mathrm{a}$ & $100,00 \mathrm{~b}$ & $91,67 \mathrm{~b}$ \\
4. Roma Gigante & $16,67 \mathrm{a}$ & $13,89 \mathrm{a}$ & $96,97 \mathrm{~b}$ & $66,67 \mathrm{~b}$ \\
5. Imperador & $33,33 \mathrm{a}$ & $27,78 \mathrm{a}$ & $100,00 \mathrm{~b}$ & $97,22 \mathrm{~b}$ \\
6. Santo Antonio & $8,33 \mathrm{a}$ & $11,12 \mathrm{a}$ & $90,67 \mathrm{~b}$ & $63,74 \mathrm{~b}$ \\
7. UTAH-20 & $68,52 \mathrm{a}$ & $66,67 \mathrm{a}$ & $100,00 \mathrm{~b}$ & $100,00 \mathrm{~b}$ \\
8. Heinz-2990 & $30,56 \mathrm{a}$ & $25,00 \mathrm{a}$ & $100,00 \mathrm{~b}$ & $91,67 \mathrm{~b}$ \\
9. IPA-3 x PSX-76 & $25,00 \mathrm{a}$ & $18,52 \mathrm{a}$ & $100,00 \mathrm{~b}$ & $84,45 \mathrm{~b}$ \\
\hline
\end{tabular}

' Médias seguidas de mesma letra não diferem entre sí em nível de $5 \%$ de probabilidade pelo teste de Tukey.

${ }^{2}$ RT, RB e RP indicam Rhizoctonia solani isolados de diferentes plantas de tomate, berinjela e pimentão, respectivamente.

Quanto ao resultado do experimento II, a análise de variância detectou pelo menos um contraste significativo entre os genótipos, em nível de $1 \%$ de probabilidade (TABELA 3).

TABELA 3. Valores e significâncias dos quadrados médios e coeficientes de variação da análise de variância do Experimento II - Reação de Genбtipos de Tomateiro a $R$. solani, em casade-vegetação.

\begin{tabular}{lccc}
\hline \hline Fontes de Variação & GL & QM & F \\
\hline Tratamentos & 72 & 4,4975 & $1,84^{\star}$ \\
Residuo & 288 & 2,4350 & \\
\hline CV (\%) & $39,54 \%$ & & \\
\hline \hline
\end{tabular}

- Significativo em nível de $1 \%$ de probabilidade pelo teste $\mathbf{F}$.

OBS: Análise feita com os dados transformados em arc sen $\sqrt{ } \%$.

Os genótipos de tomateiros apresentaram pelo teste de Tukey em nível de 5\% de probabilidade com relação a porcentagem de sobrevivencia (TABELA 4), diferenças que variaram de $90,78 \%$ para o cultivar Quinck Pick (n.58) ate 0,00\% para
- genótipo LA-462 (n.45). As introduções norteamericanas e espécies selvagens testadas apresentaram ampla variabilidade quanto aos níveis de resistência.

\section{DISCUSSÃO}

Pode-se dizer que os isolados variam em agressividade, baseando-se no conceito de VAN DER PLANK (1968). De acordo com citação de TOKESHI (1966), o conihecimento de diferentes niveis de agressividade é de grande interesse $\mathrm{em}$ trabalhos de melhoramento vegetal, pois, variedades susceptíveis, quando inoculadas com um fungo fracamente agressivo poderão mostrar-se altamente resistentes, para aquelas condições. Por outro lado, quando inoculados com linhagens de alta agressividade, poderão ser completamente destruídas. Como p6́de ser observado na TABELA 2, para qualquer que seja o genótipo escolhido, tem-se sempre a ordem de isolados $R$. solani no sentido de maior para menor capacidade de causar doença. Da mesma maneira, para qualquer isolado, não existe uma ordem diferencial para o nível de resistência. Neste caso os isolados são chamados de raças agressivas e os hospedeiros apresentam resistencia horizontal. Isto significa dizer que a resistencia horizontal $\epsilon$ uniformemente eficiente contra todas as raças do patógeno (VAN DER PLANK, 1968). 
TABELA 4 - Reação de genótipos de tomate à Rhizoctonia solani (isolado de tomateiro - RT) expressos em percentagem de sobrevivência, em casa de Vegetaçãa'.

\begin{tabular}{|c|c|c|c|c|c|}
\hline № GENÓTIPOS & $\%$ & & Ne GENÓTIPOS & & \\
\hline $58=$ Quick Pick & 90,78 & a & $75=$ GS-372 & 40,31 & opq \\
\hline 29 = Vênus PC7268 & 84,17 & b & $69=$ GS -23 & 40,24 & opq \\
\hline $79=$ BUSH-BRAGGER & 82,91 & b & $18=$ PI 128657 & 40,09 & opq \\
\hline $61=G S-20$ & 81,72 & b & $31=2-31$ & 38,91 & pqr \\
\hline $24=$ Calypso & 80,39 & $\mathbf{b}$ & $78=$ GS-356 & 38,62 & $q r$ \\
\hline $77=$ GS-28 & 74,67 & c & $44=$ Master n. 3 & 37,89 & $\mathbf{q r}$ \\
\hline $33=$ LA 1802 & 74,66 & c & $55=$ PI 126928 & 36,34 & qrs \\
\hline $10=$ Heinz -2990 & 72,29 & cd & $62=$ GS-203 & 36,01 & rs \\
\hline $30=$ Rutgers & 72,00 & cd & $03=$ Jubileu 75 & 35,77 & rst \\
\hline $80=$ GVS-1131 & 72,00 & cd & $65=$ GVS-83-006 & 35,56 & rst \\
\hline $59=$ GS -9 & 71,98 & ad & $05=$ Imperador & 33,42 & stu \\
\hline $01=$ Heline & 71,34 & cd & $04=$ Roma Gigante & 32,61 & stu \\
\hline $50=$ Jubileu 75 & 68,89 & de & $52=$ Caraibe & 31,92 & tuv \\
\hline $43=126944$ & 66,62 & ef & $39=$ LA 1800 & 31,01 & uv \\
\hline $42=$ UTAH-737 & 63,92 & f & $53=L A-371$ & 30,82 & uvx \\
\hline $02=\mathrm{NAV} 29 \backslash 115$ & 57,60 & $\mathbf{g}$ & $37=$ Olho Roxo & 30,00 & uvx \\
\hline $32=\mathrm{W} \cdot \mathrm{Va} .36$ & 55,75 & gh & $36=$ Desconhecido & 29,71 & uvxy \\
\hline $73=$ GSV -4479 & 54,93 & gh & $76=$ Valerie & 29,67 & uvxy \\
\hline $28=$ Saturn PC7267 & 54,71 & gh & $70=$ Red Express 238 & 28,89 & vxyw \\
\hline $27=$ Santa Cruz Gig. & 53,97 & ghi & $51=$ L68-S4 & 26,86 & xywz \\
\hline $38=\mathrm{W} \cdot \mathrm{Va} .63$ & 53,43 & hij & $25=$ PI 126930 & 25,84 & ywz \\
\hline $64=$ GVS-84-052 & 52,84 & hij & $74=$ GVS-84-052 & 25,04 & wz \\
\hline $23=$ Bulgaria- 12 & 50,74 & $\mathbf{i j k}$ & $57=$ GS-33 & 24,25 & $\mathbf{z} \alpha$ \\
\hline $71=$ GVS-82-44 & 50,07 & $\mathbf{i j k} \mathbf{l}$ & $17=$ PI 129146 & 23,66 & $\mathbf{z} \alpha \beta$ \\
\hline $49=\mathrm{IPA}-3$ & 49,61 & $\mathbf{j k d}$ & $67=$ GVS-82-44 & 23,48 & $z \alpha \beta$ \\
\hline $20=$ Rio Grande & 49,45 & $\mathbf{j k} \mathbf{l}$ & $21=\mathrm{RVC}-1$ & 22,15 & $\alpha \beta$ \\
\hline $46=$ Walter & 47,64 & klm & $47=$ Caribe & 20,01 & $\gamma \delta$ \\
\hline $06=$ Santo Antônio & 46,54 & $\operatorname{lmn}$ & $63=$ GS -130 & 17,08 & $\epsilon \eta$ \\
\hline $26=$ PI 126946 & 46,54 & $\operatorname{lmn}$ & $56=$ GS $\times 1$ & 16,67 & $\epsilon \boldsymbol{\eta}$ \\
\hline $22=L A-444-1$ & 46,00 & $\operatorname{lmn}$ & $11=$ IPA-3 $\times$ PSX -76 & 15,56 & $\eta$ \\
\hline $72=$ GVS-83-006 & 44,71 & $\mathrm{mn}$ & $19=$ Silvestre & 15,46 & $\eta$ \\
\hline $48=38-40$ & 44,45 & $\mathrm{mn}$ & $40=$ LA 1783 & 14,29 & $\eta$ \\
\hline $34=$ LA-2009 & 44,45 & $\mathrm{mn}$ & $41=$ LA 490 & 13,95 & $\eta$ \\
\hline $68=$ GS -22 & 43,95 & mno & $60=$ GS-27 & 7,13 & $\theta$ \\
\hline $54=$ Cal-J & 43,58 & mno & $45=$ LA 462 & 0,00 & $\kappa$ \\
\hline $09=$ Utah-20 & 42,87 & nop & & & \\
\hline
\end{tabular}

${ }^{1}$ Médias seguidas da mesma letra não diferem entre si em nível de $5 \%$ de probabilidade pelo teste Tukey. 
Desta forma, a teoria de FLOR $(1942,1971)$, de que para cada gene de resistência no hospedeiro há um gene de virulência no patógeno, não se aplicou a relação de genótipos de tomateiro $\mathrm{x}$ isolado de $R$. solani, aqui estudados. Como VAN DER PLANK $(1963,1968)$ afirmou, a resistência horizontal está presente em todos os hospedeiros, ainda não extintos pelo patógeno. Os hospedeiros testados devem possuí-la em maior ou menor nível, como mostra a TABELA 2. Não foi verificado imunidade em nenhum material avaliado, e sim níveis de resistência, onde esta, expressa por percentagem de sobrevivência, ocorreu de uma maneira contínua, desde uma reação de suscetibilidade até altos níveis de resistência.

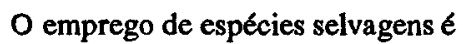
importante para o melhoramento vegetal. Embora as mesmas sejam frequentemente atacadas por patógenos, elas parecem sofrer menos que as plantas domesticadas. As plantas selvagens parecem possuir estratégias desenvolvidas que as capacitam a melhor enfrentar ataques de patógenos (CLARKE et al., 1987).

A transferência de genes provenientes de espécies selvagens para cultivares comerciais tem-se mostrado eficiente (BREWBAKER, 1969). Trabalhos visando a determinação da herança da resistência a $R$. solani seriam de grande interesse devido aos grandes prejuízos observados em regiões produtoras de tomate.

Apesar das avaliações mais reais dos componentes da resistência ao patógeno devessem ser desenvolvidas em nível de campo, experimentos em casa de vegetação podem oferecer uma idéia do comportamento do material, predizendo-se genótipos potencialmente melhores (PARLEVLIET, 1979).

Vale salientar que dispomos de poucos dados quanto às reações de cultivares de tomateiros ao tombamento por $R$. solani, assim como dos níveis de resistência das cultivares atualmente plantadas. Neste tocante, genótipos testados que apresentaram bons níveis de reação poderão ser selecionados e utilizados em futuros programas de hibridização com cultivares comerciais.

\section{AGRADECIMENTOS}

Este trabalho teve apoio do Conselho Nacional de Desenvolvimento Científico e Tecnológico (CNPq) e Coordenação de Pessoal de Nivel Superior (CAPES), Brasil.

\section{REFERÊNCIAS BIBLIOGRÁFICAS}

BAKER, K.F. Type of Rhizoctonia solani and their occurence. In: PARMETER JUNIOR, J.R., ed. Rhizocionia solani; biology and pathology. Berkeley, University of California, 1970. p.125-148.

BENSON, D.M.; BAKER, R. Epidemiology of Rhizoctonia solani preemergence damping-off of radish-survival. Phytopathology, Lancaster, v.64, p.1163-1168, 1974.

BREWBAKER, J.L. Genetica na Agricultura. São Paulo: Polígono, 1969. 224p.

CLARKE, D.D.; BEVAN, J.R.; CRUTIE, I.R. Genetic interactions between wild plants and their parasites. In: DAY, P.R.; JELLIS, G.L. eds. Genetics and Plant Pathogenisis. Oxford: Osney Mead, 1987. p.195-205.

FLOR, H.H. Inheritance of pathogenicity in Melampsora lini. Phytopathology, Lancaster, v.32, p.653-659, 1942.

FLOR, H.H. Current status of the gene-for-gene concept. Annual Review of Phytopathology, Palo Alto, v.9, p.275-296, 1971 .

KRUGNER, T.L. Doenças do eucalipto - Eucaliptus spp. In: GALLI, F. Manual de Fitopatologia, São Paulo: Ed. Agronômica Ceres, v.2., p.275-296, 1982.

MINAMI, K.; HAAG, H.P. O tomateiro. Campinas: Fundação Cargill, 1972. 352p.

PARLEVliET, J.E. Components of resistance that reduce the rate of epidemic development. Annual Review of Phytopathology, Palo Alto, v.17, p.203-222, 1979.

PARMETER JUNIOR, R.; WHITNEY, H.S. Taxonomy and nomenclature of the imperfect state. In:

Rhizoctonia solani: biology and pathology. Berkeley, University of California, 1970. p.7-19.

PARMETER JUNIOR, R.; SHERWOOD, R.T.; PLAT, W.D. Anastomosis growing among isolates of Thanatephorus cucmeris. Phytopathology, Lancaster, v.59, p.1270-1278, 1969.

SHERWOOD, R.T. Morphology and physiology in four anastomosis groups in Thanalephorus cucumeris. Phytopathology, Lancaster, v.59, p.1924-1929, 1969.

STEEL, R.D.D.; TORRIE, J.H. Principles and procedures of statistics with special references to the biological sciences. New York: McGraw-Hill, 1960. 481p. 
STEPHENS, C.T.; POWELL, C.C.; SCHMITTHENNER, A.F. A method of evaluating post-emergence damping-off pathogens of breeding plants. Phytopatology, Lancaster, v.71, p.1125-1128, 1981.

TOKESHI, H. Murcha de Fusarium em tomateiro. Estudo da variabilidade do patógeno e hospedeiro. Piracicaba, 1966. 64p. (Livre Docência) - Escola Superior de Agricultura "Luiz de Queiróz", Universidade de São Paulo.
TOKESHI, H.; CARVALHO, P.C.T. Doenças do tomateiro - Lycopersicum esculentum Mill. In: GALLI, F. Manual de Fitopatologia. São Paulo: Editora Agronômica Ceres, v.2, p.511-552, 1980.

VAN DER PLANK, J.E. Plant Disease; epidemics and control. New York: Academic Press, 1966. 349p.

VAN DER PLANK, J.E. Disease resistance in plant. New York: Academic Press, 1968. 206p.

Recebido para publicação em 08.06.93

Aceito para publicação em 14.04.94 